\title{
ВОПРОСЫ ОЦЕНКИ ДЕЯТЕЛЬНОСТИ СЛЕДСТВЕННЫХ ПОДРАЗДЕЛЕНИЙ. ЭФФЕКТИВНОСТЬ И МОТИВАЦИЯ
}

\section{QUESTIONS OF ASSESSMENT \\ OF ACTIVITIES OF INVESTIGATIVE UNITS. EFFICIENCY AND MOTIVATION}

A. Rybak

Summary. The article examines the reasons for the persistent shortage of investigative units of internal Affairs bodies. New solutions to this problem in the field of management relations are considered. In order to improve the organization of investigative management and increase employee motivation, it is proposed to introduce a new criterion for evaluating performance - efficiency. The system dynamics method is used to calculate efficiency.

Keywords: management relations, personnel policy, motivation, generational theory, system dynamics model, efficiency, throughput.

\author{
Рыбак Александр Владимирович \\ К.т.н., доцент, Дальневосточный юридический \\ институт МВД России
}

Аннотация. В статье исследуются причины устойчивого некомплекта следственных подразделений органов внутренних дел. Рассматриваются новые решения этой проблематики в области управленческих отношений. С целью совершенствования организации управления следственной деятельностью повышения мотивации сотрудников предлагается ввести новый критерий оценки деятельности - эффективность. Для расчета эффективности используется метод системной динамики.

Ключевые слова: управленческие отношения, кадровая политика, мотивация, теория поколений, модель системной динамики, эффективность, пропускная способность.
A нализ динамики оперативной обстановки за годы, прошедшие после реформирования органов внутренних дел, позволяет выявить как негативные так и позитивные тенденции по основным ее составляющим. В качестве позитивных - можно отметить достаточно стабильное за эти годы снижение зарегистрированных преступлений за исключением небольшого повышения в 2015 и 2019 годах. При этом некоторое повышение в 2019 году лежит в рамках статистической погрешности. Заметно укрепилась дисциплина в органах внутренних дел, в позитивную сторону изменилось отношение большей части населения к полиции.

В то же время, особенно в последние годы, обращает на себя внимание на первый взгляд необъяснимая (при падении уровня преступности) тенденция роста некомплекта личного состава по территориальным подразделениям уголовного розыска, следствия, дознания, участковых уполномоченных. Общение со слушателями дополнительного профессионального образования, в первую очередь с руководителями следственных подразделений, а так же с сотрудниками, выдвинутыми в резерв руководителей территориальных органов на районом уровне, дает основание полагать, что впервые проблема дефицита кадров заявила о себе около пяти лет назад, когда некоторое превышение денежного довольствия сотрудника органов внутренних дел над среднестатистической зарплатой по стране «съе- ла» инфляция, а условия труда (нагрузка, режим труда) ухудшились. Так по данным статистической отчетности в Хабаровском крае в настоящее время некомплект личного состава колеблется по этим подразделениям от 10 до $23 \%$. А с учетом отпусков по уходу за ребенком, больничных, использованию штатных должностей не по назначению процент некомплекта гораздо выше. Все это, как правило, ведет к дополнительному увеличению нагрузки на подразделение и на каждого сотрудника, в частности.

Особого внимания в этом вопросе требуют следственные подразделения. Постоянный некомплект сотрудников при жестком ограничении сроков раскрытия и расследования преступлений привносит определенные сложности в их работу. Поток реальных преступлений, совершенных на территории подразделения, в этих условиях, часто превышает возможности подразделений по их, так называемой, «переработке». Такая ситуация вынуждает следователей выискивать возможности отказа от возбуждения уголовного дела, возникает проблема укрывательства, нарушения учетно-регистрационной дисциплины. Кроме этого, есть более серьезные базисные моменты, осложняющие организацию следственного процесса в подразделениях.

Прежде всего, речь идет о ведомственных планах работы, в которых наряду с объективными целевыми параметрами, определяющими тактику и стратегию работы 
подразделения, предусмотрены показатели количества уголовных дел, которое необходимо направить в суд в отчетном периоде. Основу такого планового показателя, как правило, составляет статистический показатель предыдущего периода. Как показывает практика, «бывают случаи, когда такие плановые показатели превышают количество уголовных дел, по которым может быть завершено расследование и они могут быть направлены в суд» [3].

Такой подход формирования целей следственного подразделения, заставляет руководителя с целью выполнения поставленных задач и ускорения расследования преступлений требовать от своих подчиненных минимизировать необходимые следственные действия для принятия процессуального решения о завершении расследования.

На практике это реализуется в различных формах: отказе от профилактической работы или максимально возможного уменьшения объема следственных действий в отношении соучастников преступления, уголовные дела по которым выделены в отдельное производство. Также в процессе расследования для скорейшего его завершения часто применяется практика замены трудоемких следственных действий более простыми. Например, вместо предъявления для опознания предмета преступления, производится допрос с предъявлением предмета в качестве вещественного доказательства, либо в процессе предъявления для опознания лица очной ставкой заменяют процесс идентификации по признакам внешности и т.п.

Как правило, в результате уголовные дела, направляемые в суд, имеют значительные проблемы не только в культуре оформления, но и пробелы в расследовании, что влечет за собой активизацию контроля надзирающего прокурора и отправкой уголовного дела на дополнительное расследование. Это в свою очередь при постоянном дефиците профессиональных кадров ведет еще большему увеличении нагрузки и наступлению коллапса в организации работы следственного подразделения, когда никакие административные меры управляющего органа не могут изменить ситуацию.

Проблема усугубляется тем, что оперативная обстановка в регионах в современном информационном обществе с открытым доступам пользователей к ресурсам интернета, где изобилует информация экстремистской и террористической направленности, крайне не стабильна. Отсюда нагрузка на следователей по объективным показателям трудно поддается планированию.

Таким образом сложившаяся практика формулирования целей работы следственных подразделений на ос- нове статистических показателей предыдущего периода является тупиковым подходом. Являясь изначально средством оценки качества работы объекта управления - территориального подразделения - оно превратилось в субъект управления, цели и задачи которого не имеют ничего общего с целями и задачами органов внутренних дел.

Следует заметить, что, такая проблема проявляется во всей современной статистике. Ее можно представить как современную версию каббалы, философско-мистического учения, придающего особое значение цифре и числу. Сегодня наглядно эта активная деятельность цифровых оккультистов в мировой экономике проявляется в создании гигантских финансовых рынков, представляющих собой на 99 процентов виртуальность, описываемую с помощью бесконечного набора цифр.

Элементы такой виртуальности занимают ведущее место и имеют место и в социальном управлении, в управлении органами внутренних дел. Современный руководитель территориального подразделения вынужден большую часть своего времени затрачивать на совершенствование своих умений и навыков владения казуистикой цифровых показателей, по которым будут оценивать его работу и работу его подразделения. При этом вопросам оптимального использования имеющихся ресурсов подразделения для раскрытия и расследования преступлений в сложившейся оперативной обстановке не уделяется должного внимания.

В итоге работе следственного подразделения в условиях, когда нагрузка превышает предельно допустимую, грозит потеря управления. Его итоговые количественные показатели резко «проседают», а любые методы административного воздействия со стороны вышестоящих руководителей не приносят результата. Как следствие потеря мотивации сотрудников на добросовестный труд, отток сотрудников в другие подразделения и службы или увольнение из органов внутренних дел.

При этом дополнительного кадрового резерва в виде «скамейки для запасных» в настоящий момент не существует. Молодые люди, которые приходят и которые по возрасту (25-35 лет) потенциально могут прийти на службу в органы внутренних дел обладают несколько иными жизненными ценностями, вступающими в противоречие с требованиями, предъявляемыми к сотруднику органов внутренних дел.

Основаниями для такого умозаключения является собственный длительный опыт преподавания в вузах МВД России, а также исследования, проведенные в 1991 году американцами Нейлом Хоувом и Вильямом Штрауссом в области истории покалений. Они продела- 
ли колоссальную работу по изучению повторяющихся «поколенческих» циклов в истории США вплоть до 17 века. В итоге была сформирована теория о циклической смене поколений с повторяющимися ценностями и настроениями. Согласно этой теории наряду с профессиональными, гендерными, национальными и пр. интересами, объединяющих людей в социальные группы, каждый человек имеет «поколенческий» интерес и на основе которого формируется его способ мышления, а значит технология принятия решения. Механизмом, который создает этот интерес, являются главные факторы и события внешней среды, в которой первые двадцать лет жизни формируется личность человека. Смена поколений определяется количественными «накоплениями» факторов и событий внешней среды, меняющими способ мышления [4].

Можно спорить о научности этой теории, но практический интерес к ней в мире достаточно большой, особенно в области социального управления.

Согласно ее основным канонам поколение 25-30 летних молодых людей получило название миллениумов. Формирование этого поколения, как личностей, происходило в быстроменяющемся современном информационном обществе и сформировало у них склонность к выбору для решения только коротких по времени задач, к уходу от многоходовых комбинаций и быстрому потреблению.

Ценностью «миллениумов» является возможность быстро и без усилий достичь успеха и денежного благополучия.

Следует отметить, что современные информационные технологии для каждого молодого человека предоставляют широкий спектр возможностей для самовыражения и достижений успеха, что способствует росту эго «миллениума», он начинает чувствовать себя исключительным и неповторимым. При этом он исключает компромисс, как способ решения проблемы, быстро разочаровывается в сложной, требующей вложения большого труда, работе, считая, что его труд достоин большего. По этой причине он конфликтует с работодателями и часто меняет место работы. «При этом, «миллениумов» отличает готовность к изменениям, возможность выбора, глобальная информированность, техническая грамотность, индивидуализм, стремление учиться в течение всей жизни, неформальность взглядов, поиск простых решений, прагматизм, надежда на себя, гендерное равноправие» [4].

На основании этого для поколения «миллениумов» работа в органах внутренних дел не является привлекательной с ее ненормированным рабочим временем, жесткими условиями труда, связанными с ограничение некоторых прав и свобод гражданина, сложными и запутанными индексами оценки деятельности, завышенными требованиями к здоровью и невысоким денежным довольствием.

Таким образом, сложилось противоречие между обострившейся потребностью органов внутренних дел в квалифицированных кадровых ресурсах и отсутствием интереса к этой службе поколения «миллениумов».

Решить эту проблему можно только дополнительными мерами в сфере кадровой политики и кадровой работы.

Кадровая политика в системе МВД России осуществляется в целях формирования профессионального состава кадров, сохранения, воспроизводства, укрепления, развития, рационального и эффективного использования кадрового потенциала органов внутренних дел в интересах оперативно-служебной деятельности. Поставленные цели определяют кадровую работу как многоаспектную управленческую деятельность по решению целого комплекса экономических, социальных, нравственных, правовых, психологических и иных задач. При этом кадровая работа должна строиться с учетом необходимости поддержания баланса интересов сотрудников, с одной стороны, и органов внутренних дел в целом - с другой. Без создания гибкого мотивационного механизма решение этой задачи невозможно.

Вильям Джеймс (отец современной психологии) утверждал, что самым главным желанием всех людей является стремление быть оцененным. В этом заключена неутомимая и постоянно терзающая человека жажда.

Безусловно, процесс создания мотивационного механизма включает множество составляющих, требующих своего решения, и представляет собой управленческую проблему, разрешить которую можно лишь с течением времени и при наличии достаточного финансирования. В то же время в этой области есть вопросы, которые не требуют финансовых затрат и которые можно решить в реальном времени. Прежде всего, речь идет о необходимости перехода от оценки деятельности подразделений по конечным результатам к оценке эффективности их деятельности с учетом оптимального использования имеющихся ресурсов в рамках своих предельных возможностей.

Ныне действующий приказ № 1040 «Вопросы оценки деятельности территориальных органов Министерства внутренних дел Российской Федерации» [1] не полностью избавлен от так называемой «палочной системы» учета и не позволяет оценить эффективность деятельно- 
сти подразделения в зависимости от сложившейся в отчетном периоде оперативной обстановки.

Согласно этому приказу отдел внутренних дел оценивается по двум направлениям:

- вневедомственная оценка - оценка по результатам социологических опросов или иной информации, которая отражает мнения населения;

- ведомственная оценка, которая включает в себя экспертную оценку и оценку по результатам деятельности.

В качестве критерия оценки предлагается использовать наилучшее значение статистического показателя среди оцениваемых территориальных органов МВД России.

Статистический показатель - относительный показатель (нагрузка, удельный вес, темп роста и иные показатели), рассчитываемый на основе статистических данных и характеризующий количественные и качественные результаты деятельности территориального органа МВД России по соответствующему направлению. Сама оценка производится на основе выраженного в баллах соотношения между статистическим показателем и соответствующим критерием оценки.

Не смотря на то, что АППГ был заменен на наибольшее числовое значение показателей по группе, при подведении итогах он все равно берется для сравнения. При этом в приказе № 1040 сравнение идет не только с прошлым месяцем, но и с аналогичным периодом прошлого года.

Таким образом, анализируя последние приказы, следует отметить, что какие бы новые оценочные критерии не выбирались, итоговая оценка сводится к сравнению «палочек» сводной статистики. При этом априори считается, что все «палочки», отражающие непосредственную деятельность подразделений (статистические показатели или приведенные количественные показатели экспертной оценки), имеют одинаковую трудоемкость, хотя апостериори это не так. Действительно, трудно сравнить по трудозатратам деятельность следственной группы по расследованию многоэпизодного экономического преступления и расследование кражи сотового телефона. Но с точки зрения оценочной политики - это две абсолютно одинаковых «палки», идущих в зачет. Такой подход, безусловно, не является объективной оценкой затраченного труда подразделением и часто мотивирует его сотрудников к нарушению регистрационной дисциплины

Особый интерес в рамках этой проблематики представляют собой методы, которые позволяют количе- ственно оценить эффективность использования своих кадровых ресурсов.

В основе таких методик лежит динамическое равновесие элементов системы «преступность - ресурсы»весьма важное понятие с точки зрения разработки математических моделей кадрового обеспечения органов внутренних дел [2]

В преобразованном виде такая зависимость записывается как:

$$
\alpha=\frac{\gamma \cdot R}{V} \cdot\left(1-e^{-\frac{V}{\gamma \cdot R}}\right)
$$

где $\alpha$ - рассматривается, как показатель эффективности использования подразделением своих ресурсов, в том числе и кадровых;

$\gamma$ - показатель оптимальной или предельной (в зависимости от поставленной задачи) «пропускной способности» одного сотрудника подразделения с учетом средневзвешенной трудоемкости расследования всех преступлений, находящихся в производстве за отчетный период;

$R$ - реальная численность сотрудников подразделения;

$V$ - реальная нагрузка на подразделение в виде количества уголовных дел в производстве у следственного подразделения за отчетный период.

Для нахождения коэффициента эффективности á необходимо, прежде всего, определиться с показателем пропускной способности а̃, так как показатели $\mathrm{R}$ и $\mathrm{V}$ по отчетному периоду известны.

Методику нахождения коэффициента пропускной способности в краткой форме можно представить следующим образом:

а) после завершения отчетного периода уголовные дела классифицируются на категории по степени трудоемкости их обработки. Для этого предварительно должна быть проведена экспертная процедура, в процессе которой определяется как количество категорий, так и основные признаки, по которым будет проводиться группирование преступлений по категориям;

б) определяется доля преступлений каждой категории в общем количестве преступлений, зарегистрированных за отчетный период (пределы отклонений доли от 0 до 1);

в) по каждой категории методом экспертных оценок определяется теоретическая норма количества уголовных дел, которые способен обработать один сотрудник подразделения в течение отчетного периода (например за 1 год); 
г) коэффициент «пропускной способности» у определяется методом расчета средневзвешенной величины (в данном случае - сумма произведений доли преступлений каждой категории, умноженной на норму ее обработки).

Подставляя $\gamma$ в выражение (1), получаем своеобразную норму эффективности его работы, привязанную к особенностям оперативной обстановки, сложившейся за прошедший период. Разница между реальными показателями подразделения и его расчетной эффективностью за прошедший период определяет его рейтинг среди других подразделений.

Если реальная трудоемкость преступлений превышает расчетную средневзвешенную $\tilde{\boldsymbol{a}}$, то это может считаться объективной причиной низких итоговых результатов работы подразделения. При этом эффективность работы может оставаться высокой и соответственно высоким рейтинг подразделения.

Подводя итог изложенному, можно сделать вывод, что оценка деятельности следственных подразделений путем сравнения их итоговых результатов в виде количества преступлений переданных в суд перестала соответствовать современным требованиям организации следственной работы. Такой подход не позволяет учесть особенностей оперативной остановки на каждой территории, не позволяет учесть различия в трудоемкости раскрытия и расследования преступления.

Применение модели системной динамики (1) не только позволяет решить этот вопрос, но и выстраивает перед сотрудниками понятный и логичный механизм, по которому оценивается его работа, что способствует его мотивации на добросовестный труд.

\section{ЛИТЕРАТУРА}

1. Вопросы оценки деятельности территориальных органов Министерства внутренних дел Российской Федерации: Приказ МВД России от 31.12 .2013 № 1040. Доступ из справ.-правовой системы «Консультант Плюс».

2. Минаев В. А. Кадровые ресурсы органов внутренних дел: современные подходы к управлению. Монография.— М.: Академия МВД СССР, 1991.

3. Попова 0. А. Оценка эффективности деятельности правоохранительных органов и качество расследования преступлений // Волгоград. Современные проблемы науки и образования. 2015. № 1 (часть 1).

4. Ожиганова Е. М. Теория поколений Н. Хоува и В. Штрауса. Возможности практического применения // Бизнес-образование в экономике знаний. Иркутск. 2015. № 1.

5. Рыбак, А. В. Оценка эффективности деятельности следственных подразделений на основе применения методов системной динамики: метод. реком. Хабаровск: ДВЮИ МВД России, 2016. 